Portland State University

PDXScholar

Environmental Science and Management

Faculty Publications and Presentations

\title{
Temporal Variation in Nutrient Uptake Capacity by Intact Roots of Mature Loblolly Pine
}

\author{
Melissa S. Lucash \\ Portland State University, lucash@pdx.edu \\ J. Devereux Joslin \\ Belowground Forest Research \\ Ruth D. Yanai \\ Belowground Forest Research
}

Follow this and additional works at: https://pdxscholar.library.pdx.edu/esm_fac

Part of the Natural Resources and Conservation Commons, and the Natural Resources Management and Policy Commons

Let us know how access to this document benefits you.

\section{Citation Details}

Lucash, Melissa S.; Joslin, J. Devereux; and Yanai, Ruth D., "Temporal Variation in Nutrient Uptake Capacity by Intact Roots of Mature Loblolly Pine" (2005). Environmental Science and Management Faculty Publications and Presentations. 112.

https://pdxscholar.library.pdx.edu/esm_fac/112

This Post-Print is brought to you for free and open access. It has been accepted for inclusion in Environmental Science and Management Faculty Publications and Presentations by an authorized administrator of PDXScholar. Please contact us if we can make this document more accessible: pdxscholar@pdx.edu. 
1 Draft Copy. Copyright article published in Plant and Soil 272: 253-262.

2

3

4 Temporal Variation in Nutrient Uptake Capacity by Intact Roots of Mature

Loblolly Pine

6

$7 \quad$ Melissa S. Lucash ${ }^{1}$, J. Devereux Joslin ${ }^{2}$ and Ruth D. Yanai ${ }^{1}$

10 'Department of Forest and Natural Resources, State University of New York,

11 College of Environmental Science and Forestry, Syracuse, N.Y. 13210, 503-846-

12 9122, 315-470-6954 (FAX), mslucash@syr.edu, and ²Belowground Forest

13 Research, Apartado 104-5655, Santa Elena de Monteverde, Puntarenas, Costa

14 Rica

15

16 Running head: Nutrient uptake of loblolly pine

17

18 Number of text pages: 31

19 Number of tables: 1

20 Number of figures: 3

21

22 
1 Key words: nitrogen, nitrate, ammonium, potassium, magnesium, calcium,

2 loblolly pine, nutrient uptake, nutrient uptake capacity, seasonality

\section{Abstract}

5 Nutrient uptake is generally thought to exhibit a simple seasonal pattern, but few

6 studies have measured temporal variation of nutrient uptake capacity in mature

7 trees. We measured net uptake capacity of $\mathrm{K}, \mathrm{NH}_{4}{ }^{+}, \mathrm{NO}_{3}{ }^{-}, \mathrm{Mg}$ and $\mathrm{Ca}$ across a

8 range of solution concentrations by roots of mature loblolly pine at Calhoun

9 Experimental Forest in October 2001, July 2001, and April 2002. Uptake

10 capacity was generally lowest in July; rates in October were similar to those in

11 April. Across a range of concentrations, antecedent nutrient solution

12 concentrations affected the temporal patterns in uptake in July but not in October

13 or April. In July, uptake of $\mathrm{NH}_{4}^{+}, \mathrm{Mg}$ and $\mathrm{Ca}$ was positively correlated with

14 concentration when roots were exposed to successively lower concentrations,

15 but negatively correlated with concentration when exposed to successively

16 higher concentrations. In contrast, uptake in October was constant across the

17 range of concentrations, while uptake increased with concentration in April. As in

18 studies of other species, we found greater uptake of $\mathrm{NH}_{4}+$ than $\mathrm{NO}_{3}$. Temporal

19 patterns of uptake capacity are difficult to predict, and our results indicate that

20 experimental conditions, such as experiment duration, antecedent root conditions

21 and nutrient solution concentration, affect measured rates of nutrient uptake. 


\section{Introduction}

2 The seasonality of nutrient uptake by roots affects fertilizer use efficiency, soil

3 solution concentrations, and stream export of nutrients. For example, the timing

4 of fertilizer application to fast-growing trees, such as loblolly pine (Pinus taeda

5 L.), is critical to maximize nutrient uptake and storage capacity (Miller, 1981;

6 Johnson and Todd, 1988). Since some studies have shown that less than $15 \%$

7 of nitrogen fertilizer applied may be retained by trees (Heilman and Gessel, 1963;

8 Van Miegroet et al., 1994), understanding what controls the timing of uptake is

9 important to minimize nutrient leaching into groundwater and streams and to

10 maximize fertilizer use efficiency.

11 Plant growth and foliar nutrients vary during the growing season (Nelson

12 et al., 1970; Adams et al., 1987; Valentine and Allen, 1990), but these patterns

13 may not reflect seasonal patterns of nutrient uptake because a significant fraction

14 of nutrients are remobilized from within the plant (Millard and Proe, 1992; Proe et

15 al., 2000). Such remobilization enables plants to grow during periods of low

16 nutrient availability and uptake (Millard, 1994).

17 Temporal patterns of ion uptake in trees have been measured primarily

18 using seedlings, and simple seasonal trends have been observed. Nitrogen

19 uptake of young Pinus radiata (D. Don) in the field was higher in spring and

20 summer than autumn and winter (Smethurst and Nambiar, 1989). Phosphorus

21 uptake of three-year-old Picea sitchensis (Bongard) Carrière grown in the

22 greenhouse was similar in spring and late summer (Proe and Millard, 1995). 
Mature trees may differ from seedlings in their temporal pattern of uptake,

2 since plant age affects root anatomy (Eissenstat and Achor, 1999; Wells and

3 Eissenstat, 2003), root respiration (Wells and Eissenstat, 2003), and nitrogen

4 and phosphorus uptake capacity (Dong et al., 2001; Wells and Eissenstat, 2003).

5 Only one study to date has examined temporal trends in uptake using intact roots

6 of mature trees. Net ammonium uptake was highest in the summer in subalpine

7 Fagus sylvatica L. (beech) and Picea abies (L.) Karst (spruce) (Gessler et al., 8 1998).

9 Temporal patterns in nutrient uptake through the year are driven by

10 variations in soil nutrient availability and the plant's capacity to take up nutrients.

11 These factors are not independent, since plants regulate uptake capacity based

12 on nutrient supply (Lee, 1982; Drew et al., 1984; BassiriRad et al., 1993). Plants

13 have high $\mathrm{NO}_{3}$ - uptake rates following a period of deficiency (Lee and Rudge,

14 1986; Siddiqi et al., 1989), and exhibit low uptake after exposure to high $\mathrm{NO}_{3}{ }^{-}$

15 concentrations, due to saturation of exchange sites at the root surface (Dean-

16 Drummond, 1982; Siddiqi et al., 1990).

17 We examined nutrient uptake capacity in a commercially important conifer,

18 loblolly pine, by exposing roots to known concentrations of nutrient solutions .

19 Using this approach, changes in uptake capacity over time can be measured

20 independent of variation in ambient soil solution concentrations and soil moisture

21 conditions. The objective of our study was to quantify temporal variation in

22 potassium, ammonium, nitrate, magnesium and calcium uptake capacity by

23 measuring net uptake across a range of nutrient concentrations in July, October 
1 and April. We hypothesized that uptake capacity would decline between late

2 summer and fall and then increase to a maximum in spring. We also examined

3 how uptake differed with experimental conditions, such as nutrient solution

4 concentration, experiment length and antecedent nutrient solution concentration.

5 We expected net nutrient uptake rates to increase with nutrient solution

6 concentration and experiment duration. We also predicted that uptake capacity

$7 \quad$ would be higher when plants were given low antecedent nutrient solution

8 concentrations. Finally, we compared the time course of $\mathrm{NH}_{4}{ }^{+}$and $\mathrm{NO}_{3}{ }^{-}$uptake,

9 predicting that uptake of $\mathrm{NH}_{4}{ }^{+}$would be more rapid than that of $\mathrm{NO}_{3}^{-}$.

\section{Materials and methods}

\section{Study area}

13 This study was conducted in the Calhoun Experimental Forest of the Sumter

14 National Forest in Union County, South Carolina $\left(82^{\circ} \mathrm{N}, 34.5^{\circ} \mathrm{W}\right)$. Annual

15 precipitation averages $1228 \mathrm{~mm}(1971-2000)$ and mean annual temperature is

$1615^{\circ} \mathrm{C}$ (Administration, 2002). Soils are well-developed Ultisols of the series

17 Appling and Cataula (clayey, mixed, thermic Typic Kanhapludults, (Overstreet

18 and Bell, 1965). Soils are acidic with low exchangeable $\mathrm{Ca}$ and $\mathrm{Mg}$, especially in

19 the upper $15 \mathrm{~cm}\left(0.05 \mathrm{cmolc} \mathrm{kg}^{-1} \mathrm{Ca}\right.$ and $0.02 \mathrm{cmolc} \mathrm{kg}^{-1} \mathrm{Mg}$ ) (Markewitz et al.,

20 1998). Average concentrations of $\mathrm{NH}_{4}-\mathrm{N}$ and $\mathrm{NO}_{3}-\mathrm{N}$ were low in soil solutions

21 collected from the forest floor $\left(35 \mu \mathrm{mol}_{\mathrm{c}} \mathrm{L}^{-1} \mathrm{NH}_{4}-\mathrm{N}\right.$ and $\left.10 \mu \mathrm{mol}_{\mathrm{c}} \mathrm{L}^{-1} \mathrm{NO}_{3}-\mathrm{N}\right)$ and

22 from $15 \mathrm{~cm}\left(8 \mu \mathrm{mol}_{\mathrm{c}} \mathrm{L}^{-1} \mathrm{NH}_{4}-\mathrm{N}\right.$ and $\left.3 \mu \mathrm{mol}_{\mathrm{c}} \mathrm{L}^{-1} \mathrm{NO}_{3}-\mathrm{N}\right)$. Virtually no nitrogen in

23 either form was detected below $60 \mathrm{~cm}$ depth (Markewitz et al., 1998). 
1 Cumulative precipitation was $285 \mathrm{~mm}, 350 \mathrm{~mm}$, and $463 \mathrm{~mm}$ for the two weeks

2 preceding our measurements in July, 2001, October 2001, and April 2002,

3 respectively (NOAA Administration, 2002). Mean daily high (low) temperatures

4 were $28^{\circ} \mathrm{C}\left(19^{\circ} \mathrm{C}\right)$ in July; $19^{\circ} \mathrm{C}\left(7^{\circ} \mathrm{C}\right)$ in October and $19{ }^{\circ} \mathrm{C}\left(5^{\circ} \mathrm{C}\right)$ in April.

5 Cotton (Gossypium hirsutum L.), corn (Zea maize L.) and wheat (Triticum

6 aestivum L.) were grown at the site for many decades prior to 1954 (Urrego,

7 1993). Loblolly pine seedlings were planted at Calhoun in 1956 . The rate of

8 biomass accumulation was highest from 1966-1976, and total biomass reached a

9 peak of 211-247 $\mathrm{Mg} \mathrm{ha}^{-1}$ in 1984 (Markewitz et al., 1998). Total live biomass has

10 recently declined, reaching $174 \mathrm{Mg} \mathrm{ha}^{-1}$ in 2000 (D. Richter, pers. comm.) as a

11 result of mortality from southern pine beetle (Dendroctonus frontalis) attacks and

12 wind damage from heavy storms.

14 Overview of methods

15 Nutrient uptake capacity of loblolly pine roots was measured using the depletion

16 technique (Rennenberg et al., 1996; Gessler et al., 1998; BassiriRad et al.,

17 1999). We carefully excavated terminal fine root branches of loblolly pine near

18 the soil surface. Fine root branches of loblolly pine were identified to species by

19 tracing them to coarse roots, which differed in color and texture from roots of

20 understory deciduous trees and shrubs. Root branches used in our experiments

21 were composed of roots primarily less than $2 \mathrm{~mm}$ in diameter, which are

22 considered most active in nutrient uptake. These excavated root branches 
1 contained mycorrhizal short roots, but most of the extramatrical hyphae were

2 severed during the excavation and cleaning process.

3 During excavation, we washed roots with deionized water to remove soil

4 particles and adhering organic matter. Each root was placed in a 50-ml tube

5 containing $27 \mathrm{ml}$ of nutrient solution. Nutrient solutions were prepared in the

6 laboratory, using concentrations based on data from soil solution collected by

7 low-tension lysimeters at $15 \mathrm{~cm}$ (Markewitz et al., 1998). Nutrient concentrations

8 were intended to represent a range of values from one to ten times the average

9 soil solution concentrations ( $1 \mathrm{X}, 3 \mathrm{X}, 5 \mathrm{X}, 7 \mathrm{X}, 10 \mathrm{X})$. The actual concentrations

10 differed somewhat from the predicted values. In our analyses, we used the actual

11 concentrations to which the root branches were exposed (Table 1). Tubes

12 containing nutrient solution but no roots were used as controls to determine the

13 amount of evaporation and contamination that occurred during the experiments.

14 Tubes with and without roots were covered with parafilm to reduce evaporation

15 and were aerated with ambient air using a battery-powered pump system

16 comprised of tubing linked to pipette tips inserted in the tubes. Nutrient solutions

17 were collected after specified intervals, and the volume of solution was measured

18 in order to correct for uptake or evaporation of water. Solutions were filtered on

19 site using syringe filters with $0.4 \mu \mathrm{m}$ membrane filters. Samples were

20 transported in coolers to the laboratory where they were frozen until analysis.

21 After the uptake experiments were completed, the portion of the root immersed in

22 the solution was severed from the tree, weighed, and stored in $50 \%$ ethanol.

23 Roots were weighed after oven-drying at $70{ }^{\circ} \mathrm{C}$. 
Nitrate and $\mathrm{NH}_{4}{ }^{+}$concentrations were determined by continuous flow

2 analyzer and autoanalyzer (model AA3; Bran and Luebbe, Norderstedt,

3 Germany). Cation $\left(\mathrm{Ca}^{+2}, \mathrm{Mg}^{+2}\right.$, and $\left.\mathrm{K}^{+}\right)$concentrations were determined using

4 inductively coupled plasma emission spectroscopy (model FMA-03, Spectro

5 Analytical Instruments, Kleve, Germany). Net nutrient uptake rates were

6 calculated from the change in nutrient content of the solution (concentration

7 times volume) over the time period. Rates were expressed as a function of dry

8 weight for each root. Since we did not measure influx and efflux independently,

9 our rates are expressed as net uptake rates with positive values indicating net

10 uptake of nutrients and negative values indicating net efflux of nutrients. These

11 rates include any change in nutrient storage by microbes on the roots, which we

12 could not control, but was probably small. Contamination and evaporation were

13 also generally small; the $\mathrm{K}, \mathrm{NH}_{4}^{+}, \mathrm{NO}_{3}^{-}, \mathrm{Mg}$ and $\mathrm{Ca}$ concentrations of controls

14 were not significantly different from the initial concentration in $72 \%$ of the cases.

16 Temporal trends in uptake

17 In July 2001, October 2001 and April 2002, 10 loblolly pine root branches were

18 excavated, washed with deionized water and placed in a 50-ml tube with $27 \mathrm{ml}$ of

19 nutrient solution. A 15-ml tube was inserted into the $50-\mathrm{ml}$ tube to displace

20 solution and increase the ratio of root surface area to solution volume.

21 To determine if uptake capacity was affected by antecedent nutrient

22 solution concentration, we initially exposed half of the roots to average soil

23 solution concentrations ( $1 \mathrm{X})$ and the remaining roots to $10 \mathrm{X}$ solutions (Table 1 ). 
1 Following the initial two-hour period, each root branch was removed and placed

2 in a new tube containing a new solution. Roots exposed to $1 \mathrm{X}$ were subjected

3 over successive 2-h intervals to increasing concentrations of solutions

4 (approximately 3X, 5X, 7X and 10X; Table 1). The remaining roots were

5 exposed to concentrations of solution decreasing from 10X to 1X. Since two

6 days were needed to excavate the roots and implement the treatments, we

7 exposed all roots to the same nutrient solution concentration (5X) overnight for

815 to 19 hours.

9

10 Comparison of $\mathrm{NH}_{4}^{+}$and $\mathrm{NO}_{3}^{-}$uptake in spring

11 In March 2001, we excavated 12 terminal fine root branches of loblolly pine.

12 Roots were washed with deionized water and placed in a $50-\mathrm{ml}$ tube with $30 \mathrm{ml}$

13 of nutrient solution. Four roots were randomly allocated to each nutrient solution

14 concentration: $1 \mathrm{X}, 5 \mathrm{X}$ and $20 \mathrm{X}$. Five $\mathrm{ml}$ aliquots of solution were removed from

15 the nutrient solution after $14 \mathrm{~h}, 29 \mathrm{~h}$ and $100 \mathrm{~h}$. Following each aliquot removal,

$165 \mathrm{ml}$ of deionized water was added to the tubes to keep volume constant and

17 provide a descending sequence of concentrations. The nutrient solutions were

18 filtered and frozen until analysis. Since the roots from this experiment were

19 accidentally discarded before analysis, we present changes in nutrient

20 concentration over time but not uptake per unit root.

\section{Statistical analysis}

22 To determine how sampling date (July, October or April) and prior treatment

23 (increasing or decreasing sequence of concentration treatments) affected uptake 
1 capacity, data were analyzed using generalized linear models (SAS Institute,

2 1985) with nutrient solution concentration treatment (1X, 3X, 5X, 7X, 10X) as a

3 repeated measure. Since the 3-way interaction of sampling date, prior treatment

4 and concentration was significant for most solutes at $\alpha=0.05$, we compared

5 temporal trends at our mid-range concentration (5X) at both 2-hour and overnight

6 time intervals. We also compared the slopes of the regression lines of uptake

$7 \quad$ with concentration between sampling dates and between prior treatments.

8 To determine how concentration changed with time in our March 2001

9 comparison of $\mathrm{NH}_{4}+$ and $\mathrm{NO}_{3}^{-}$, we used time as a class variable in our model.

10 Since each root was only given one concentration in our preliminary experiment,

11 data for each concentration (1X,5X and 20X) were analyzed separately.

\section{Results}

14 The analysis of our measurements of $\mathrm{K} \mathrm{NH}_{4}{ }^{+}, \mathrm{NO}_{3}-\mathrm{Mg}$ and $\mathrm{Ca}$ uptake at five

15 different nutrient concentrations (1X, 3X, 5X, 7X, 10X) and two different

16 antecedent condition in three months of the growing season resulted in a three-

17 way interaction of concentration, antecedent condition and time of year for most

18 nutrients. We first present temporal variation in net uptake capacity at our mid-

19 range concentration (5X) to show how uptake varied with experiment duration

20 and sampling date. Next, we discuss the effects of antecedent conditions and

21 nutrient solution concentration on temporal trends of uptake capacity. Finally, we

22 compare the rates of $\mathrm{NH}_{4}{ }^{+}$and $\mathrm{NO}_{3}-$ uptake. 
1

3 April, when plants at this location are most physiologically active, and lowest in

4 October. Surprisingly, net uptake of $\mathrm{K}$ and $\mathrm{NH}_{4}+$ at the $5 \mathrm{X}$ concentration was

5 similar in April and October (Figure 1). In July, efflux of $\mathrm{K}$ and $\mathrm{NH}_{4}+$ exceeded

6 uptake. Net uptake of $\mathrm{Mg}$ and $\mathrm{Ca}$ was positive at all sampling dates, and the

7 rates were statistically indistinguishable across dates. High variation among

8 roots precluded detection of differences smaller than $4 \mu \mathrm{mol} \mathrm{gdwt}{ }^{-1} \mathrm{~h}^{-1}$ for $\mathrm{Mg}$

9 and $7 \mu \mathrm{mol} \mathrm{gdwt}^{-1} \mathrm{~h}^{-1}$ for Ca.

11 Temporal trends of net uptake capacity at $5 X$ in overnight experiments

12 We also examined how net uptake of $\mathrm{K} \mathrm{NH}_{4}{ }^{+}, \mathrm{NO}_{3}-\mathrm{Mg}$ and $\mathrm{Ca}$ differed in July,

13 October and April when roots were left in solution for 15-19 h. The comparisons

14 of uptake across the three seasonal times were similar between $2 \mathrm{~h}$ and

15 overnight experiments, except for $\mathrm{NH}_{4}{ }^{+}$(Figure 1). Ammonium uptake did not

16 vary by sampling date in the overnight experiments, because nearly all of the

$17 \mathrm{NH}_{4}(92 \%)$ was taken up in the first two hours.

18 Nitrate was measured only in the overnight experiments since uptake

19 rates were too low to be detectable in $2 \mathrm{~h}$. As expected, net nitrate uptake was

20 highest in April (Figure 1). In July and October, efflux of $\mathrm{NO}_{3}^{-}$exceeded uptake.

$21 \quad$ Uptake of $\mathrm{Mg}$ and $\mathrm{Ca}$ was higher in the $2 \mathrm{~h}$ than overnight experiments, not

22 because there was not enough solute remaining in the tubes to sustain uptake at 23 the 2-hr rate as observed with $\mathrm{NH}_{4}{ }^{+}$. In fact, the final concentration of $\mathrm{K}, \mathrm{Mg}, \mathrm{Ca}$ 
1 in the tubes was similar in the overnight (averaging $241 \mu \mathrm{M} \mathrm{K}, 82 \mu \mathrm{M} \mathrm{Mg}$ and 85

$2 \mu \mathrm{M} \mathrm{Ca})$ and the $2 \mathrm{~h}$ experiments $(233 \mu \mathrm{M} \mathrm{K}, 75 \mu \mathrm{M} \mathrm{Mg}$ and $70 \mu \mathrm{M} \mathrm{Ca})$. The

3 average rate of net uptake $\left(\mu \mathrm{mol} g d w t^{-1} h^{-1}\right)$ is thus much lower for the overnight

4 experiments although the net amount of uptake $\left(\mu \mathrm{mol} \mathrm{gdwt}^{-1}\right)$ was similar. This

5 suggests that net uptake was positive for no more than 2 hours, after which efflux

6 equaled influx.

7

8 Effects of antecedent conditions on temporal trends of net uptake capacity

9 To examine how antecedent conditions affect net uptake, we exposed our roots

10 to either increasing ( $1 \mathrm{X}$ to $10 \mathrm{X})$ or decreasing (10X to $1 \mathrm{X})$ nutrient solution

11 concentrations. We found that the sequence of treatments affected uptake rates

12 of $\mathrm{NH}_{4}+, \mathrm{Mg}$ and $\mathrm{Ca}$ in July but not in October or April. In July, antecedent

13 conditions affected the relationship between uptake and concentration for $\mathrm{NH}_{4}{ }^{+}$

$14(p=0.03), \mathrm{Mg}(p<0.0001)$ and $\mathrm{Ca}(p=0.01)$. In contrast to our prediction, roots

15 exposed to initially high concentrations ("decreasing") had higher uptake of $\mathrm{NH}_{4}{ }^{+}$,

$16 \mathrm{Mg}$ and $\mathrm{Ca}$ than roots exposed to lower concentrations first ("increasing", Figure

17 2). In July, $\mathrm{K}$ uptake was relatively constant across concentration and was

18 unaffected by antecedent nutrient concentrations.

19 In October and April, net uptake was not affected by antecedent root

20 conditions, but the pattern of uptake with concentration differed between these

21 two sampling times. Although we predicted that uptake would increase with

22 concentration, uptake of $\mathrm{Ca}, \mathrm{Mg}, \mathrm{K}$ and $\mathrm{NH}_{4}{ }^{+}$was relatively constant across

23 concentration in October (Figure 2). In April, when plant roots may be more 
1 physiologically active, $\mathrm{Ca}, \mathrm{Mg}, \mathrm{K}$ and $\mathrm{NH}_{4}{ }^{+}$uptake significantly increased with

2 nutrient solution concentration $\left(R^{2}=0.56,0.75,0.36\right.$, and 0.38 respectively).

4 Timing of net $\mathrm{NO}_{3}{ }^{-}$and $\mathrm{NH}_{4}{ }^{+}$uptake

5 We predicted that net $\mathrm{NH}_{4}+$ uptake of loblolly pine roots would exceed net $\mathrm{NO}_{3}{ }^{-}$

6 uptake in our March 2001 experiment. During the first 14 hours, $\mathrm{NH}_{4}^{+}$was

7 rapidly depleted at all three initial concentrations $(p=<0.0001$ at $1 \mathrm{X}, p=<0.0001$

8 at $5 \mathrm{X}, p=0.03$ at $20 \mathrm{X}$; Figure 3 ). At $5 \mathrm{X}$ and $1 \mathrm{X}, \mathrm{NH}_{4}{ }^{+}$concentrations dropped by

$998 \%$ and $96 \%$ after only $14 \mathrm{~h}$. Even at the highest concentration (20X), average

$10 \mathrm{NH}_{4}{ }^{+}$concentration dropped by $60 \%$ after $14 \mathrm{~h}$, and solutions were $97 \%$ depleted 11 at $100 \mathrm{~h}$.

12 In contrast, net $\mathrm{NO}_{3}{ }^{-}$uptake was delayed. In the first $14 \mathrm{~h}$, there was no

13 significant net uptake, and nitrate efflux exceeded nitrate uptake at all

14 concentrations (Figure 3). Between 14 and $100 \mathrm{hrs}$, depletion of at least $89 \%$

15 occurred at all three concentrations ( $p=0.02$ at $1 \mathrm{X}, p=0.04$ at $5 \mathrm{X}, p=0.004$ at

16 20X), indicating that net nitrate uptake capacity was induced after an initial lag

17 period.

18

19 Discussion

20 Nutrient accumulation in trees is generally thought to vary seasonally, with

21 maximum uptake of nitrogen in summer (Millard and Proe, 1992; Millard, 1994;

22 Gessler et al., 1998) and of cations (K, Mg and Ca) in spring (Stassen and

23 Stadler, 1988). We measured uptake capacity, rather than uptake at ambient 
1 conditions, in our study with loblolly pine at Calhoun Experimental Forest to

2 determine whether changes in uptake capacity might contribute to changes in

3 nutrient accumulation over time. We found that uptake capacity did not follow the

4 seasonal pattern expected of plant nutrient accumulation.

5 In general, $\mathrm{NH}_{4}{ }^{+}$and $\mathrm{NO}_{3}{ }^{-}$uptake capacity in mature loblolly at Calhoun

6 was lower in July than April. In contrast, $\mathrm{N}$ accumulation was lower in spring

7 than summer in sand-grown Picea sitchensis (Millard and Proe, 1992) and field-

8 grown P. sitchensis and Acer pseudoplatanus (Millard, 1994). In those studies,

9 remobilized $\mathrm{N}$ apparently satisfied plant demand for $\mathrm{N}$ in spring, while uptake

10 supplied $\mathrm{N}$ in summer. Although different species were used, these studies

11 demonstrate that seasonal patterns of nutrient uptake capacity may differ from

12 those of nutrient accumulation.

13 Temporal patterns in uptake have sometimes been attributed to variation

14 in soil temperature. Intact roots of subalpine beech and spruce had their highest

$15 \mathrm{NH}_{4}+$ uptake in July and uptake was significantly correlated with soil temperature

16 (Gessler et al., 1998). In contrast, we observed low uptake capacity in July when

17 air temperature was highest. Uptake capacity may have been limited by soil

18 water availability in July, though the roots were in nutrient solutions when we

19 measured uptake. Since we measured uptake at ambient temperatures, we

20 cannot address how temperature affects uptake capacity independent of other

21 seasonally varying environmental factors.

22 Nitrate uptake of mature loblolly pine was negligible in the 2-h experiments

23 and extremely low in the overnight experiments, indicating that short-term 
1 measurements of $\mathrm{NO}_{3}{ }^{-}$uptake may not be providing reliable estimates of uptake

2 capacity in mature trees. In a previous study, nitrate uptake by subalpine spruce

3 and beech was generally not detectable if measured over a 4-h time interval

4 (Gessler et al., 1998). Since $\mathrm{NO}_{3}{ }^{-}$concentrations in soil solution ranged from

5 only 3 to $10.1 \mu \mathrm{molc}_{\mathrm{C}} \mathrm{L}^{-1} \mathrm{NO}_{3}-\mathrm{N}$ in the top $15 \mathrm{~cm}$ at Calhoun (Markewitz et al.,

6 1998), nitrate reductase activity may have been low in the loblolly pine roots ( $\mathrm{Li}$

7 and Gresshoff, 1990). The nitrate present in the nutrient solution should increase

8 nitrogen reductase activity, but induction and transport to the roots may take

9 several hours. In our longest experiment, we induced $\mathrm{NO}_{3}^{-}$uptake sometime

10 between 14 and $100 \mathrm{~h}$ (Figure 3).

11 Since $\mathrm{NH}_{4}^{+}$can inhibit $\mathrm{NO}_{3}^{-}$influx (Lee and Drew, 1989) and induce $\mathrm{NO}_{3}{ }^{-}$

12 efflux (Dean-Drummond and Glass, 1983), the low rates of net $\mathrm{NO}_{3}-$ uptake we

13 observed may have been affected by $\mathrm{NH}_{4}+$ in the nutrient solution. Ammonium

14 uptake occurred at a much faster rate than $\mathrm{NO}_{3}^{-}$, a result that agrees with

15 previous studies showing a preference for $\mathrm{NH}_{4}+$ by conifers (Cole, 1981;

16 Rygiewicz and Bledsoe, 1986; Gijsman, 1990; Marschner et al., 1991;

17 BassiriRad et al., 1997; Gessler et al., 1998). The higher capacity for uptake of

$18 \mathrm{NH}_{4}{ }^{+}$than $\mathrm{NO}_{3}{ }^{-}$may be an adaptation to the greater availability of $\mathrm{NH}_{4}{ }^{+}$in the

19 forest floor at Calhoun (Markewitz et al., 1998) or it may reflect the lower

20 energetic costs of uptake and assimilation of $\mathrm{NH}_{4}{ }^{+}$relative to $\mathrm{NO}_{3}{ }^{-}$(Bloom et al., 21 1992).

22 Potassium uptake capacity was highest in the spring, consistent with

23 observations of K accumulation in peach trees (Stassen and Stadler, 1988). 
1 Seasonal changes in $\mathrm{K}$ uptake have been studied primarily using young fruit

2 trees (Gries et al., 1993; Picchioni et al., 1997) and agricultural crops (Clark and

3 Smith, 1992; Hocking, 1994); more studies are needed to assess seasonal

4 changes in uptake by mature forest trees.

$5 \quad$ Although $\mathrm{K}$ efflux of roots may indicate hypoxic conditions (Escamilla and

6 Comerford, 1998), all roots were aerated in our study. We observed net K efflux

7 by loblolly pine in July but not October or April. In a previous study, however,

8 intact slash pine roots took up K in July (Escamilla and Comerford, 1998).

9 Differences in starting concentrations do not explain the differences in uptake.

10 We observed net $\mathrm{K}$ efflux by loblolly pine at concentrations of $48 \mu \mathrm{M}$ while slash

11 pine roots took up K at $25.6 \mu \mathrm{M}$ (Escamilla and Comerford, 1998).

12 Root disturbance may be partly responsible for the $\mathrm{K}$ efflux in our study.

13 Slash pine roots were excavated six months prior to measurement by Escamilla

14 and Comerford (1998), while the plant roots in our study were excavated just

15 prior to analysis. In previous studies, root disturbance stimulated $\mathrm{NO}_{3}{ }^{-}$efflux

16 (Aslam et al., 1996) and decreased uptake of $\mathrm{K}, \mathrm{NH}_{4}{ }^{+}$and $\mathrm{NO}_{3}{ }^{-}$(Bloom and

17 Caldwell, 1988). Exposing roots to different pretreatments designed to minimize

18 disturbance, however, did not decrease cation efflux by mature sugar maple, red

19 pine and Norway spruce (McFarlane and Yanai, In press).

20 There were no statistically significant temporal variations in the capacity

21 for uptake of $\mathrm{Ca}$ and $\mathrm{Mg}$ by mature loblolly pine at Calhoun. No studies to date

22 have examined seasonal trends in $\mathrm{Ca}$ and $\mathrm{Mg}$ uptake by roots, although studies 
1 of seasonal changes in foliar concentrations indicate that plant demand is higher

2 in spring and summer than in fall (Gries et al., 1993).

3 Nutrient uptake capacity is sometimes observed to follow saturation

4 kinetics (Epstein, 1976). We found that the relationship between uptake and

5 concentration, when there was one, was generally linear, such that uptake would

6 be best described with a slope and intercept. Our most important finding,

7 however, was that uptake kinetics were not constant over time, such that using a

8 relationship measured at one point in time could fail to predict rates at another

9 point in time.

10 Experimental conditions, such as nutrient solution concentration and

11 experiment length, may affect uptake rates observed in the field. In our study,

$12 \mathrm{NH}_{4}{ }^{+}$uptake $\left(-3.6 \mu \mathrm{mol} \mathrm{gdwt}^{-1} \mathrm{~h}^{-1}\right)$ was much lower than previously reported for

13 intact roots of loblolly pine in August $\left(18.8 \mu \mathrm{mol} \mathrm{gdwt}^{-1} \mathrm{~h}^{-1}\right)$ (BassiriRad et al.,

14 1997). That study used higher concentrations $\left(1700 \mu \mathrm{mol} \mathrm{L}^{-1}\right)$ than ours $(5$ - 92

$\left.15 \mu \mathrm{mol} \mathrm{L}^{-1}\right)$ and a longer exposure time (24 h, compared to our $2 \mathrm{~h}$ ).

16 In our study, net uptake rates of $\mathrm{NH}_{4}{ }^{+}, \mathrm{Mg}$ and $\mathrm{Ca}$ declined with exposure

17 times. Declining $\mathrm{NH}_{4}{ }^{+}$uptake rates over time were associated with depletion of

$18 \mathrm{NH}_{4}+$ in the applied solution. In contrast, $\mathrm{Mg}$ and $\mathrm{Ca}$ concentrations were similar

19 at the end of the $2 \mathrm{~h}$ as compared to the overnight experiments, suggesting that

20 net uptake was negligible after the first $2 \mathrm{~h}$. Declining uptake rates of $\mathrm{Mg}$ and $\mathrm{Ca}$

21 could be associated with the duration of the experiments or with attaining a

22 concentration below which net uptake was not possible. In any case, it can be 
1 misleading to report uptake rates as instantaneous rates, when the duration of

2 experiments has such significant effects on uptake.

3 Species may differ in their uptake rates, even when experimental

4 conditions are similar. In July, spruce and beech roots had higher average $\mathrm{NH}_{4}{ }^{+}$

5 uptake rates $\left(1.4,0.9 \mu \mathrm{mol} \mathrm{gfw}^{-1} \mathrm{~h}^{-1}\right)($ Gessler et al., 1998) than loblolly pine in

6 our study $\left(-4.0 \mu \mathrm{mol} \mathrm{gfw}{ }^{-1} \mathrm{~h}^{-1}\right)$ when trees were exposed to similar $\mathrm{NH}_{4}^{+}$

7 concentrations (approximately $55 \mu \mathrm{M}$ ). In April, however, our loblolly pine had

8 higher uptake rates $\left(2.9 \mu \mathrm{mol} \mathrm{gfw}^{-1} \mathrm{~h}^{-1}\right)$ than spruce $\left(0.02 \mu \mathrm{mol} \mathrm{gfw}^{-1} \mathrm{~h}^{-1}\right)$, and

9 beech $\left(0.3 \mu \mathrm{mol} \mathrm{gfw}^{-1} \mathrm{~h}^{-1}\right)$ Gessler et al. (1998).

10 This is the first study to show that the effects of antecedent conditions on

11 uptake capacity vary temporally. Antecedent nutrient conditions influenced root

12 uptake in July but not in October or April. In July, loblolly pine roots exposed to

13 high initial concentrations had high $\mathrm{NH}_{4}{ }^{+}, \mathrm{Mg}$ and $\mathrm{Ca}$ uptake rates, indicating that

14 the roots may have been exposed to low levels of these elements in the soil

15 (Lee, 1993). Roots exposed to successively higher concentrations had lower

16 uptake at high concentrations, due perhaps to saturation of exchange sites at the

17 root surface (Dean-Drummond, 1982; Siddiqi et al., 1990).

18 The technique used in this study to obtain intact roots required removal of

19 the roots from the surrounding soil, which disrupts the extramatrical hyphae of

20 mycorrhizae. Since ectomycorrhizae play an important role in nutrient uptake of

21 loblolly pine seedlings (Smith and Read, 1997), additional studies are needed to

22 assess the importance of mycorrhizae on the temporal pattern of nutrient uptake

23 capacity of mature trees. 


\section{Acknowledgements}

3 We are grateful to Ruth Sherman, Lisa Montana, Karis McFarlane, Sarah Kulpa,

4 Don Bickelhaupt, and Dan McLean for their assistance in the field and the

5 laboratory. We also thank Tim Fahey for use of his autoanalyzer and Erik

6 Hobbie for comments on this manuscript. Finally, Dan Richter and Dan

7 Markewitz provided access to the study site and background data about the site.

8 Financial support was provided by the National Science Foundation through

9 grants DEB-0087263 and 9211768.

10 


\section{References}

2 Adams M B, Campbell R G, Allen H L and Davey C B 1987 Root and foliar nutrient concentrations in loblolly pine: effects of season, site, and fertilization. For. Sci. 33, 984-996.

5 Aslam M, Travis R L, Rains D W and Huffaker R C 1996 Effect of root perturbation and excision on nitrate influx and efflux in barley (Hordeum vulgare) seedlings. Physiol. Plant. 97, 425-432.

8 BassiriRad H, Griffin K L, Reynolds J F and Strain B R 1997 Changes in root $\mathrm{NH}_{4}{ }^{+}$and $\mathrm{NO}_{3}{ }^{-}$absorption rates of loblolly and ponderosa pine in response to $\mathrm{CO}_{2}$ enrichment. Plant Soil. 190, 1-9.

11 BassiriRad H H, Caldwell M M and Bilbrough C 1993 Effects of soil temperature and nitrogen status on kinetics of ${ }^{15} \mathrm{NO}_{3}$ - uptake by roots of field-grown Agropyron desertorum (Fisch. ex Link) Schult. New Phytol. 123, 485-489.

14 BassiriRad H H, Prior S A, Norby R J and Rogers H H 1999 A field method of determining $\mathrm{NH}_{4}{ }^{+}$and $\mathrm{NO}_{3}{ }^{-}$uptake kinetics in intact roots: effects of $\mathrm{CO}_{2}$

Bloom A J and Caldwell R M 1988 Root excision decreases nutrient absorption enrichment on trees and crop species. Plant Soil. 217, 195-204.

19 Bloom A J, Sukrapanna S S and Warner R L 1992 Root respiration associated 20 with ammonium and nitrate absorption and assimilation by barley. Plant $21 \quad$ Physiol. 99, 1294-1301.

22 Clark C J and Smith G S 1992 Seasonal dynamics of biomass and mineral nutrient partitioning in mature kiwifruit vines. Ann. Bot. 70, 229-237. 
1 Cole D W 1981 Nitrogen uptake and translocation by forest ecosystems. In F E

2 Clark and T Rosswall. Terrestrial nitrogen cycles. Processes, ecosystem

3 strategies and management impacts. Stockholm, Swedish Natural

$4 \quad$ Science Research Council.219-232.

5 Dean-Drummond C E 1982 Mechanisms for nitrate uptake into barley (Hordeium

$6 \quad$ vulgare cv. fergus) seedlings grown at controlled nitrate concentrations in

7 the nutrient medium. Plant Science Letters. 24, 79-89.

8 Dean-Drummond C E and Glass A D M 1983 Short term studies of nitrate uptake 9 into barley plants using ion-specific electrodes and ${ }^{36} \mathrm{ClO}_{3}{ }^{-} \mathrm{II}$. Regulation of

$10 \quad \mathrm{NO}_{3}^{-}$efflux by $\mathrm{NH}_{4}^{+}$. Plant Physiol. 73, 105-110.

11 Dong S, Scagel C F, Cheng L, Fuchigami L H and Rygiewicz P T 2001 Soil

12 temperature and plant growth stage influence nitrogen uptake and amino

13 acid concentration of apple during early spring growth. Tree Physiol. 21,

$14 \quad 541-547$.

15 Drew M C, Saker L R, Barber S A and Jenkins W 1984 Changes in kinetics of

16 phosphate and potassium absorption in nutrient-deficient barley roots

17 measured by solution-depletion technique. Planta. 160, 490-499.

18 Eissenstat D M and Achor D S 1999 Anatomical characteristics of roots of citrus

19 rootstocks that vary in specific root length. New Phytol. 141, 309-321.

20 Epstein E 1976 Kinetics of ion stransport and the carrier concept. In U Luttge and

$21 \quad$ M G Pitman. Encyclopedia of plant physiology. Berlin, Springer-Verlag.

$22 \quad$ IIB.70-94. 
1 Escamilla J A and Comerford N B 1998 Measuring nutrient depletion by roots of 2 mature trees in the field. Soil Sci. Soc. Am. J. 62, 797-804.

3 Gessler A, Schneider S, Von Sengbusch D, Weber P, Hanemann U, Huber C,

$4 \quad$ Rothe A, Kreutzer K and Rennenberg H 1998 Field and laboratory

5 experiments on net uptake of nitrate and ammonium by the roots of

6 spruce (Picea abies) and beech (Fagus sylvatica) trees. New Phytol. 138, $7 \quad 275-285$.

8 Gijsman A J 1990 Soil water content as a key factor determining the source of

9 nitrogen $\left(\mathrm{NH}_{4}^{+}\right.$or $\left.\mathrm{NO}_{3}^{-}\right)$absorbed by Douglas-fir (Psuedotsuga menziesii)

10 and the pattern of rhizosphere $\mathrm{pH}$ along its roots. Can. J. For. Res. 21, $11 \quad 616-625$.

12 Gries C, Kimball B A and Idso S B 1993 Nutrient uptake during the course of a 13 year by sour orange trees growing in ambient and elevated carbon dioxide 14 concentrations. J. Plant Nut. 16, 129-147.

15 Hawkins B J, Kiiskila S B R and Henry G 1999 Biomass and nutrient allocation in

16 Douglas-fir and amabilis fir seedlings: influence of growth rate and

17 temperature. Tree Physiol. 19, 59-63.

18 Heilman P E and Gessel S P 1963 Nitrogen requirements and the biological 19 cycling of nitrogen in Douglas-fir stands in relationship to the effects of 20 nitrogen fertilization. Plant Soil. 18, 386-401.

21 Hocking P J 1994 Dry-matter production, mineral nutrient concentrations, and 22 nutrient distribution and redistribution in irrigated spring wheat. J. Plant $23 \quad$ Nut. 17, 1289-1308. 
1 Johnson D W and Todd D E 1988 Nitrogen fertilization of young yellow poplar

2 and loblolly pine plantations at differing frequencies. Soil Sci. Soc. Am. J.

$3 \quad 52,1468-1477$.

4 Lee R B 1982 Selectivity and kinetics of ion uptake by barley plants following $5 \quad$ nutrient deficiency. Ann. Bot. 50, 429-449.

6 Lee R B 1993 Control of net uptake of nutrients by regulation of influx in barley

7 plants recovering from nutrient deficiency. Ann. Bot. 72, 223-230.

8 Lee R B and Drew M C 1989 Rapid, reversible inhibition of nitrate influx in barley

9 by ammonium. J. Exp. Bot. 40, 741-752.

10 Lee R B and Rudge K A 1986 Effects of nitrogen deficiency on the absorption of

11 nitrate and ammonium by barley plants. Ann. Bot. 57, 471-486.

12 Li Z Z and Gresshoff P M 1990 Developmental and biochemical regulation of

13 'constitutive' nitrate reductase activity in leaves of nodulating soybean. J.

$14 \quad$ Exp. Bot. 41, 1231-1238.

15 Markewitz D, Richter D D, Allen H L and Urrego J B 1998 Three decades of

16 observed soil acidification in the Calhoun Experimental Forest: has acid

17 rain made a difference? Soil Sci. Soc. Am. J. 62, 1428-1439.

18 Marschner H, Haussling M and George E 1991 Ammonium and nitrate uptake

19 rates and rhizosphere $\mathrm{pH}$ in non-mycorrhizal roots of Norway spruce

20 [Picea abies (L.) Karst.]. Trees. 5, 14-21.

21 McFarlane $\mathrm{K} \mathrm{J}$ and Yanai $\mathrm{R} \mathrm{D}$ In press Measuring nitrogen and phosphorus

22 uptake by intact roots of mature sugar maple, red pine, and Norway

23 spruce. Tree Physiol. 
1 McKinnon M L, Auiring D T and Bauce E 1998 Influence of resource availability

2 on growth and foliar chemistry within and among young white spruce

3 trees. Ecoscience. 5, 295-305.

4 Millard P 1994 Measurement of the remobilization of nitrogen for spring leaf 5 growth under field conditions. Tree Physiol. 14, 1049-1054.

6 Millard P and Proe M F 1992 Storage and internal cycling of N in relation to

7 seasonal growth of sitka spruce. Tree Physiol. 10, 33-43.

8 Miller H G 1981 Forest fertilization: some guiding concepts. Forestry. 54, 157$9 \quad 167$.

10 Nelson L, Switzer G and Smith W 1970 Dry matter and nutrient accumulation in 11 young loblolly pine (Pinus taeda L.). In Tree Growth in Forest Soils, Proc.

12 Third North Am. For. Soils Conf., 1968.261-273.

13 NOAA Administration 2002 Climate data- Greenville/Spartanburg Airport.

14 Greenville, SC.Overstreet W C and Bell H I 1965 The crystalline rocks of 15 South Carolina.

16 Picchioni G A, Brown P H, Weinbaum S A and Muraoka T T 1997 Macronutrient

17 allocation to leaves and fruit of mature, alternate-bearing pistachio trees:

18 magnitude and seasonal patterns at the whole-canopy level. Journal of

19 American Horticultural Society. 122, 267-274.

20 Proe M F, Midwood A J and Craig J 2000 Use of stable isotopes to quantify

21 nitrogen, potassium and magnesium dynamics in young Scots pine (Pinus

22 sylvestris). New Phytol., 461-469. 
1 Proe M F and Millard P 1995 Effect of N supply upon the seasonal partitioning of $2 \quad \mathrm{~N}$ and $\mathrm{P}$ uptake in young Sitka spruce (Picea sitchensis). Can. J. For. Res. 25, 1704-1709.

4 Rennenberg H, Schneider S and Weber P 1996 Analysis of uptake and allocation 5 of nitrogen and sulfur compounds by trees in the field. J. Exp. Bot. 47, $6 \quad 1491-1498$.

7 Rygiewicz P T and Bledsoe C S 1986 Effects of pretreatment conditions on 8 ammonium and nitrate uptake by Douglas-fir seedlings. Tree Physiol. 1, $9 \quad 145-150$.

10 SAS Institute 1985 SAS user's guide. SAS Institute, Cary, NC.

11 Siddiqi M Y, Glass A D M, Ruth T J and Fernando M 1989 Studies of the regulation of nitrate influx by barley seedlings using ${ }^{13} \mathrm{NO}_{3}$. Plant Physiol. $1390,1426-1432$.

14 Siddiqi M Y, Glass A D M, Ruth T J and Rufty T W 1990 Studies of the uptake of 15 nitrate in barley. I. Kinetics of ${ }^{13} \mathrm{NO}_{3}{ }^{-}$influx. Plant Physiol. 90, 1426-1432.

16 Smethurst P J and Nambiar E K S 1989 An appraisal of the in situ soil-core technique for measuring nitrogen uptake by a young Pinus radiata plantation. Soil Biol. Biochem. 21, 939-942.

19 Smith S E and Read D J 1997 Mycorrhizal symbiosis. Academic Press, San 20 Diego.

21 Stassen P J C and Stadler J D 1988 Seasonal uptake of phosphorus, potassium, 22 calcium and magnesium by young peach trees. South African J. of Plant 23 and Soil. 5, 19-23. 
1 Urrego M J B. 1993. Nutrient accumulation in biomass and forest floor of a 342 year-old loblolly pine plantation. Dept of Forestry. Raleigh, NC, North $3 \quad$ Carolina State Univ.

4 Valentine D W and Allen H L 1990 Foliar responses to fertilization identify 5 nutrient limitation in loblolly pine. Can. J. For. Res. 20, 144-151.

6 Van Miegroet H, Norby R J and Tschaplinski T J 1994 Nitrogen fertilization

7 strategies in a short rotation sycamore plantation. For. Ecol. Man. 64, 13824.

9 Wells C E and Eissenstat D M 2003 Beyond the roots of young seedlings: the 10 influence of age and order on root physiology. Journal of Plant Growth 11 Regulation. 21, 324-334.

12 


\section{Figure Legends}

2 Figure 1. Uptake of $\mathrm{K}, \mathrm{NH}_{4}^{+}, \mathrm{NO}_{3}^{-}, \mathrm{Mg}$, and $\mathrm{Ca}$ by intact roots of mature loblolly

3 trees, expressed on a per dry-weight of root per hour basis, in July 2001, October

42001 and April 2002 at concentrations five times higher than lysimeter soil

5 solution concentrations ( $5 X)$. Roots were left in solution for a 2-h interval and

6 overnight (15-19 h). In the case of $\mathrm{NO}_{3}{ }^{-}$, only overnight data is presented. Error

7 bars show standard errors of the mean $(n=10)$. Means with different letters differ

8 significantly at $\alpha \leq 0.05$.

9

10 Figure 2. Uptake of $\mathrm{K}, \mathrm{NH}_{4}^{+}, \mathrm{Mg}$ and $\mathrm{Ca}$ on a dry-weight basis by intact roots of

11 mature loblolly trees as a function of nutrient solution concentration in July 2001,

12 October 2001 and April 2002. Measurements were conducted over $2 \mathrm{~h}$

13 intervals. In July, uptake was significantly different when roots were exposed to

14 successively higher concentrations (increasing,-----. ) than successively lower

15 (decreasing, - ) concentrations. In October and April, there was no

16 difference in uptake based on antecedent concentrations and therefore only lines

17 for regressions that are significantly different from zero $(p \leq 0.05)$ are shown

18 through all the data $(n=10)$. None of the regressions for October were

19 statistically significant.

20

21 Figure 3. Time course of $\mathrm{NH}_{4}{ }^{+}$and $\mathrm{NO}_{3}{ }^{-}$concentration over a 100 -h period using

22 intact roots of mature loblolly pine trees in March 2001 exposed to three initial

23 concentrations (1X,5X, 20X). Error bars show standard errors of the mean 
$1 \quad(n=10)$. Concentrations were diluted by additions of distilled water at each

2 sampling time. 
1 Table 1. Average concentration ( $1 \mathrm{X}$ to $10 \mathrm{X})$ to which the roots were exposed in

2 July 2001, October 2001 and April 2002. Concentrations were based on soil

3 solution data at a depth of $15 \mathrm{~cm}$ at Calhoun Experimental Forest, SC (Target

4 1X; Markewitz et al., 1998). Values are expressed as the average concentration

$5(\mu M)$ and standard error $(n=30$, except for Target $1 X$ where $n=8)$.

6

Average concentration ( \pm SE)

$(\mu \mathrm{M})$

\begin{tabular}{ccccc}
\hline Conc. & $\mathrm{K}$ & $\mathrm{NH}_{4}{ }^{+}$ & $\mathrm{Mg}$ & $\mathrm{Ca}$ \\
\hline $1 \mathrm{X}$ & $46 \pm 2$ & $10 \pm 1$ & $19 \pm 5$ & $28 \pm 5$ \\
$3 \mathrm{X}$ & $133 \pm 9$ & $31 \pm 6$ & $60 \pm 13$ & $88 \pm 30$ \\
$5 \mathrm{X}$ & $223 \pm 16$ & $40 \pm 1$ & $100 \pm 19$ & $185 \pm 27$ \\
$7 \mathrm{X}$ & $350 \pm 10$ & $60 \pm 6$ & $156 \pm 20$ & $156 \pm 45$ \\
$10 \mathrm{X}$ & $408 \pm 24$ & $78 \pm 12$ & $360 \pm 32$ & $360 \pm 71$ \\
Target $1 \mathrm{X}$ & $39 \pm 4$ & $8 \pm 4$ & $21 \pm 2$ & $33 \pm 3$ \\
& & & &
\end{tabular}




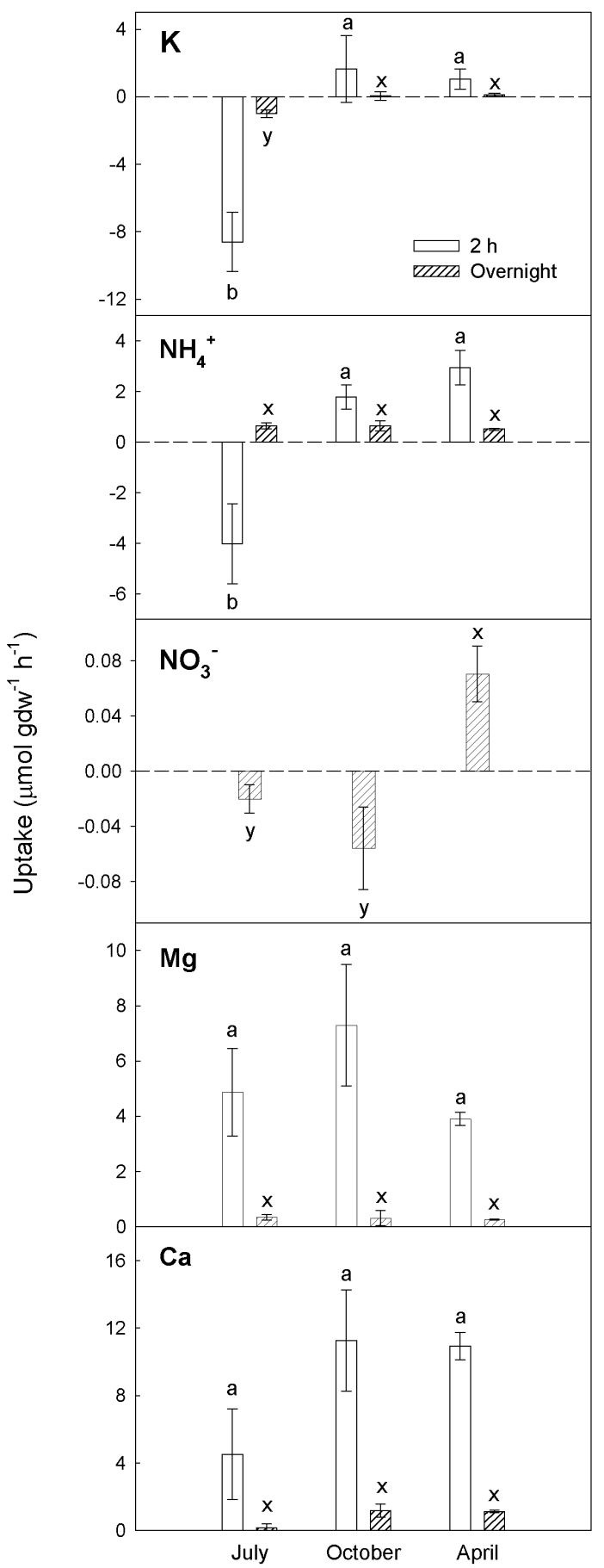




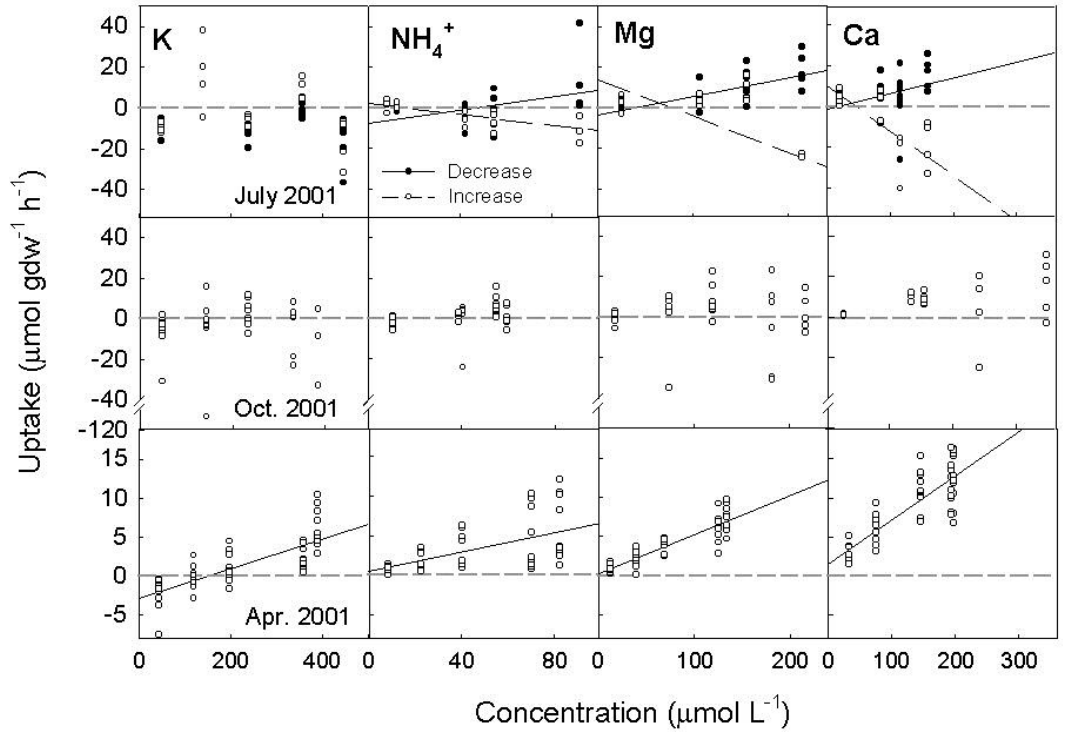




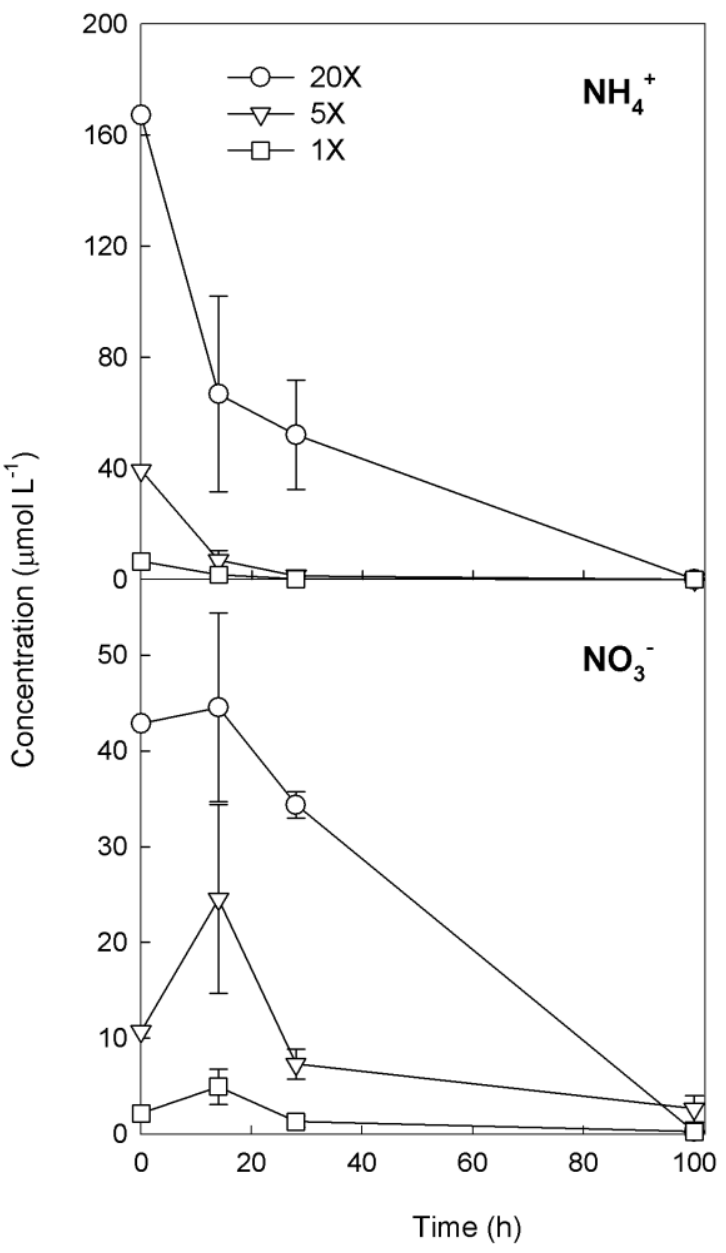

